\title{
Lisboa-Porto, ida e volta. Diário de bordo sobre marionetas em dois festivais (FIMFA e FIMP 2016)
}

CATARINA FIRMO

LISBOA. 5 A 23 DE MAIO. FESTIVAL INTERNACIONAL DE MARIONETAS E FORMAS ANIMADAS. MARIONETAS ENTRE CIRCO E GUERRA

La marionnette est une parole qui agit.

PAUL CLAUDEL

Alargar as fronteiras da marioneta e reconhecê-la «cada vez mais permeável a outros campos artísticos $»^{1}$ tem sido a missão do FIMFA ao longo dos últimos dezasseis anos. Nesta edição, manteve-se como divisa a versatilidade das formas animadas convocadas em cena sob diferentes perspectivas, como a dança, o vídeo, o circo e as instalações plásticas.

No FIMFA de 2016, começámos no circo, com um convite para enfrentar o medo do disforme, do excêntrico e do insólito. Palhaços e marionetas têm andado juntos ao longo dos tempos, em rotas de mascarados e saltimbancos, cúmplices nas suas missões de encantamento e transgressão popular. O FIMFA não se esqueceu dessa cumplicidade, logo com o espectáculo de abertura Les encombrants font leur cirque do Théâtre de la Licorne e em seguida com a dupla de palhaços em Clourophobia, pela companhia britânica Pickled Image. Marionetas e palhaços desafiam-nos a rir e a transgredir as regras.

Les encombrants font leur cirque é um espectáculo que dá continuidade ao trabalho desenvolvido em Le bestiaire forain, criado há doze anos. Animais, máquinas animadas e figuras fantásticas partilham a arena de um circo ambulante com uma família de velhos artistas. As marionetas à escala humana são incorporadas pelos intérpretes dissimulados e vestidos de negro, funcionando como sombras, ao serviço da forma animada que manipulam. São verdadeiras esculturas que nos transportam para universos de fantasia, onde se cruzam ecos de Júlio Verne, Leonardo Da Vinci e as máquinas dos Royal de Luxe. Latas de sardinha fazem trapézio, um louva-a-deus é equilibrista; caracóis, pririlampos e rinocerontes

1 Programa FIMFA 2016. 




SMOOTH LIFE, ENC. HUSAM ABED, SÃO LUIZ TEATRO MUNICIPAL, 2016, [F] IRENA VOdÁKOVÁ

são algumas das criaturas que povoam o palco, onde a escrita cénica é feita «de carne, papel e ferro velho», de acordo com a marca estílistica de Claire Dancoisne.

Em Clourophobia, dois palhaços (Dik e Adam) acordam capturados num mundo de cartão, onde todo o cenário e objetos em palco estão forrados com caixotes. Explorados pelo palhaço Poco, improvisam situações num compasso de espera, recorrendo à participação dos espectadores, também eles capturados neste universo insólito. Uma espectadora é chamada ao palco para cortar o cabelo, depois é a vez de um grupo de pessoas a quem são servidos cocktails e instrumentos musicais de cartão, compondo uma banda de espectadores apanhados de surpresa. Se o público 


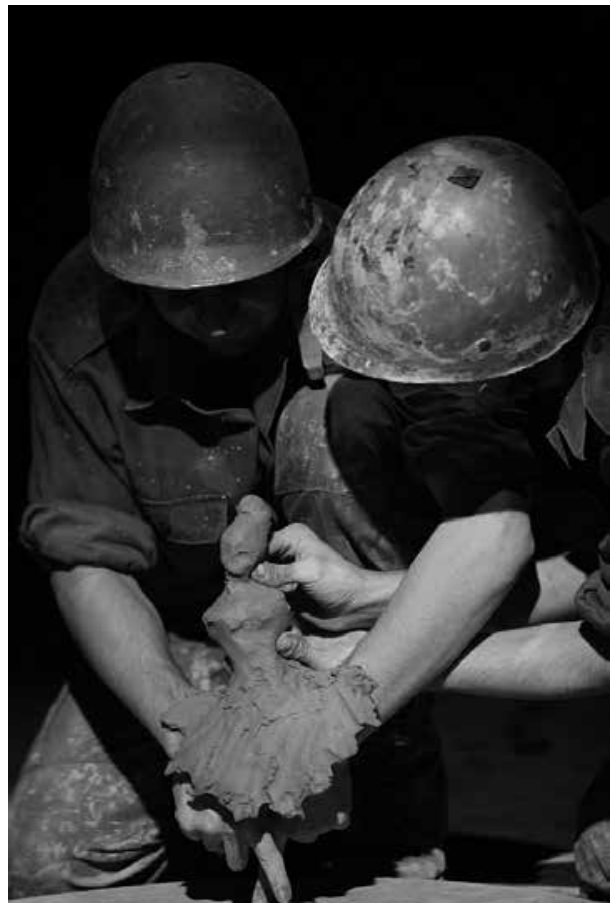

COUNT TO ONE, ENC. YASE TAMAM, SÃO LUIZ TEATRO MUNICIPAL, 2016, [F] MANI LOTFIZADEH

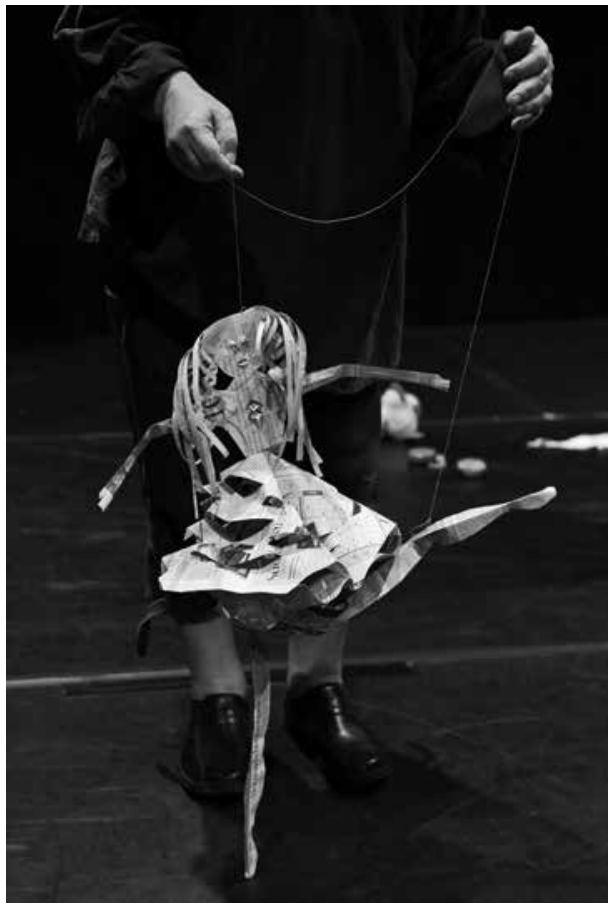

CABARET BERLINN, ENC. PETER WASCHINSKY, MOSTEIRO DE SÃO BENTO DA VITÓRIA, 2016, [F] SUSANA NEVES

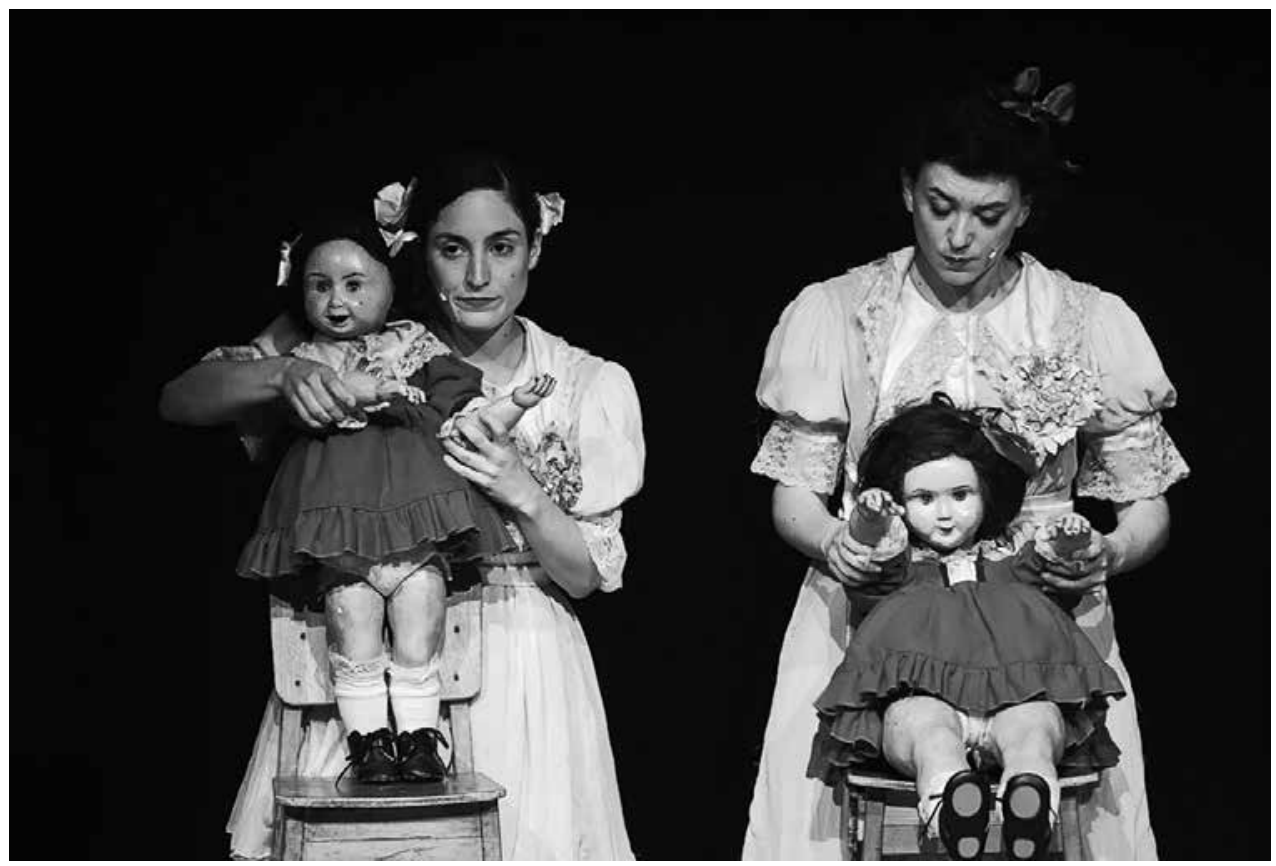

HOUSE BY THE LAKE, ENC. YAEL RASOOLY, SÃO LUIZ TEATRO MUNICIPAL, 2016, [F] ALÍPIO PADILHA 
é recorrentemente chamado ao palco, também os palhaços invadem a plateia em ímpetos repentinos que nos deslocam do papel de espectadores passivos, desafiando-nos com spray serpentina fluorescente.

Saímos do circo e passamos aos objectos do quotidiano, arquivados, tirados das gavetas e dos bolsos da memória, brinquedos esquecidos, secções de perdidos e achados, objectos resgatados dos esconderijos, dos armários, das coisas guardadas, umas vezes com zelo e outras por acaso. Em Objecto Encontrado Perdido do Teatro de Ferro, reflectimos sobre o modo como as coisas ocupam o espaço, o tempo, o corpo e a memória. Num espectáculo que explora as diferentes possibilidades de hibridismos da marioneta, a partir do teatro físico e visual, mantém-se um questionamento da ideia de manipulação subjacente. Experimentam-se diferentes possibilidades para expressar o envolvimento corporal do manipulador e o modo como a matéria transforma o corpo, ele próprio matéria em movimento e produtor de imagens. É também a matéria agregada ao corpo do intérprete que se explora em Les intimités de l'homme orchestre. Santiago Moreno apresenta-nos uma mão orquestra que, com os seus apetrechos metálicos, é simultaneamente um instrumento musical e uma insólita personagem, produtora de som, movimento e ressonância com copos, lâmpadas e outros objectos frágeis e cristalinos. O Homem-Orquestra surge ainda na festa de encerramento do festival, com mais de doze instrumentos ligados a diferentes partes do corpo, através de sistemas de fios e roldanas, despedindo-se de Lisboa com boleros, cumbias e bossa nova. Em Singpspiele, mantém-se o desafio de transformar o corpo através da matéria. A coreógrafa Maguy Marin, que associamos inevitavelmente à criação May $B$ de 1981, afasta-se neste espectáculo dos corpos espectros de Samuel Beckett, continuando a explorar as metamorfoses do corpo e do rosto, a partir do trabalho de máscara do bailarino-actor David Mambouch, que desfila com um flip book uma panóplia de rostos conhecidos e desconhecidos, experimentando diferentes identidades.

As marionetas convidam-nos ainda a viajar no tempo, em espectáculos como Tutu, onde percorremos momentos da História da dança nas décadas de 1930 e 1940, com lanternas mágicas e um par de sapatos vermelhos que nos conduz entre as duas guerras mundiais, a dançar sapateado, tango, vaudeville, ballet clássico e ballet bauhaus. Pares complementares de marionetas e actores incitam-nos ainda a rescrever histórias do passado com mais humor, onirismo e finais felizes, como é o caso das Marionetas do Porto, que contam às crianças uma versão divertida de Barba Azul. 
Os mesmos palcos que acolheram marionetas de escala humana, de sombra, objectos quotidianos e utilitários dão também lugar às formas animadas em miniatura, capazes de percorrer as obras completas de Shakespeare em Muito Barulho por Nada, de David Espinosa, e de demonstrações científicas com The Assembly of Animals, de Tim Spooner. Nestas criações assumem-se as formas de espectáculo-instalação, com a exposição de esculturas performativas, ambos criados por artistas plásticos que cederam ao fascínio das formas animadas.

Depois de irmos ao circo, de revirarmos os baús do passado e viajarmos no tempo, despertamos em palcos de guerra, onde ainda é possível sentarmo-nos juntos para jantar, criar pássaros e bailarinas de barro, cantar, fazer ballet e brincar com bonecas. Com Smooth Life, somos convidados para jantar e ouvir a história de Husam Abed, um palestino nascido e criado no campo de refugiados de Baqaa, na Jordânia. Nos almoços de família de Husam, eram sempre nove à mesa e às vezes havia makloba, prato típico da Palestina com arroz, beringela e galinha. Neste espectáculo intimista, Husam cozinha makloba para oito espectadores, enquanto conta histórias da sua vida, da sua família e das suas memórias, que têm como pano de fundo os acontecimentos políticos do seu país, através de marionetas, objectos, fotografias, vídeos, mapas e grãos de arroz que indicam o caminho. Em Count to One, a iraniana Zahra Khyali Sabri, inspirada nos versos do poeta persa Omar Khayam, apresenta outro espectáculo que se assume como declaração contra a guerra, onde três soldados decidem deixar de combater, passando a comunicar através de esculturas de barro. No espectáculo de encerramento House of the Lake, é a vez da israelita Yael Roosoly se insurgir contra a devastação do Holocausto, pelo contraste com o onirismo e fantasia de três crianças que, apesar de confinadas à clausura de um esconderijo, projectam os seus sonhos e fantasias, brincando, fazendo ballet, dando vida às suas bonecas, últimos vestígios de um passado de paz e inocência. Arroz, barro e bonecas são matérias-primas de fantasia em palcos de utopia que permitem resgatar a vida e os seus rituais, manter a esperança e continuar a sonhar. 
Faites l'inventaire de vos poches, de votre sac. Interrogez-vous sur la provenance, l'usage et le devenir de chacun des objets que vous en retirez. Questionnez vos petites cuillères. GEORGES PEREC

O teatro de marionetas tem cada vez menos bonecos, e os que surgem em cena habituaram-se a partilhar o palco com os actores, os materiais e até os elementos da cenografia e os objectos mais improváveis vindos dos bastidores e zonas técnicas, como cabos, fios eléctricos, caixotes do lixo e microfones que se cansaram de estar fora de cena. O FIMP mantém-se atento a esta tendência do teatro de marionetas cada vez mais híbrido, num esforço de ampliar as suas fronteiras, com criações que convocam as matérias e a sua habitação no espaço cénico, confrontando-as com as «extensões concretas e imaginadas do corpo - dos objectos de utilização quotidiana ou outros que alguém decidiu coleccionar, dos mistérios da voz humana à estranheza-familiar das próteses mecânicas, passando pelo registo ou o rasto de determinado gesto ou acção», lemos no programa.

O jogo de espelhos de Fernando Pessoa e os seus heterónimos inaugurou esta edição do FIMP, com a criação Não Sei o Que o Amanhã Trará, da Limite Zero. A trama identitária do poeta desdobrado nas suas personas encontra nas marionetas um solo fértil e cúmplice ao seu anseio de transformação e metamorfose. Pessoa é recriado como um espelho partido, e as marionetas de diferentes dimensões, escalas e matérias (miniatura, luva, vara, sombra e vídeo) reflectem os seus fragmentos e estilhaços. Sem deixarmos este jogo de espelhos, somos conduzidos num labirinto de duplos e reflexos com o espectáculo A Procura de Lem, do Teatro de Ferro. Uma cientista entrega a cada espectador uma máscara e leva-nos por corredores sombrios até ao laboratório do escritor Stanisław Lem, procurado por terrorismo intelectual e substituído por um robô. Partilhando o espaço cénico com os actores, somos estimulados a reinventar modos de resistência e a viver um movimento colectivo. Somos cúmplices e reféns de Lem neste espectáculo, mas também parceiros activos do acto de criação. E é ainda num jogo de espelhos que entramos na criação de Raquel André O Segredo de Simónides - Colecção 


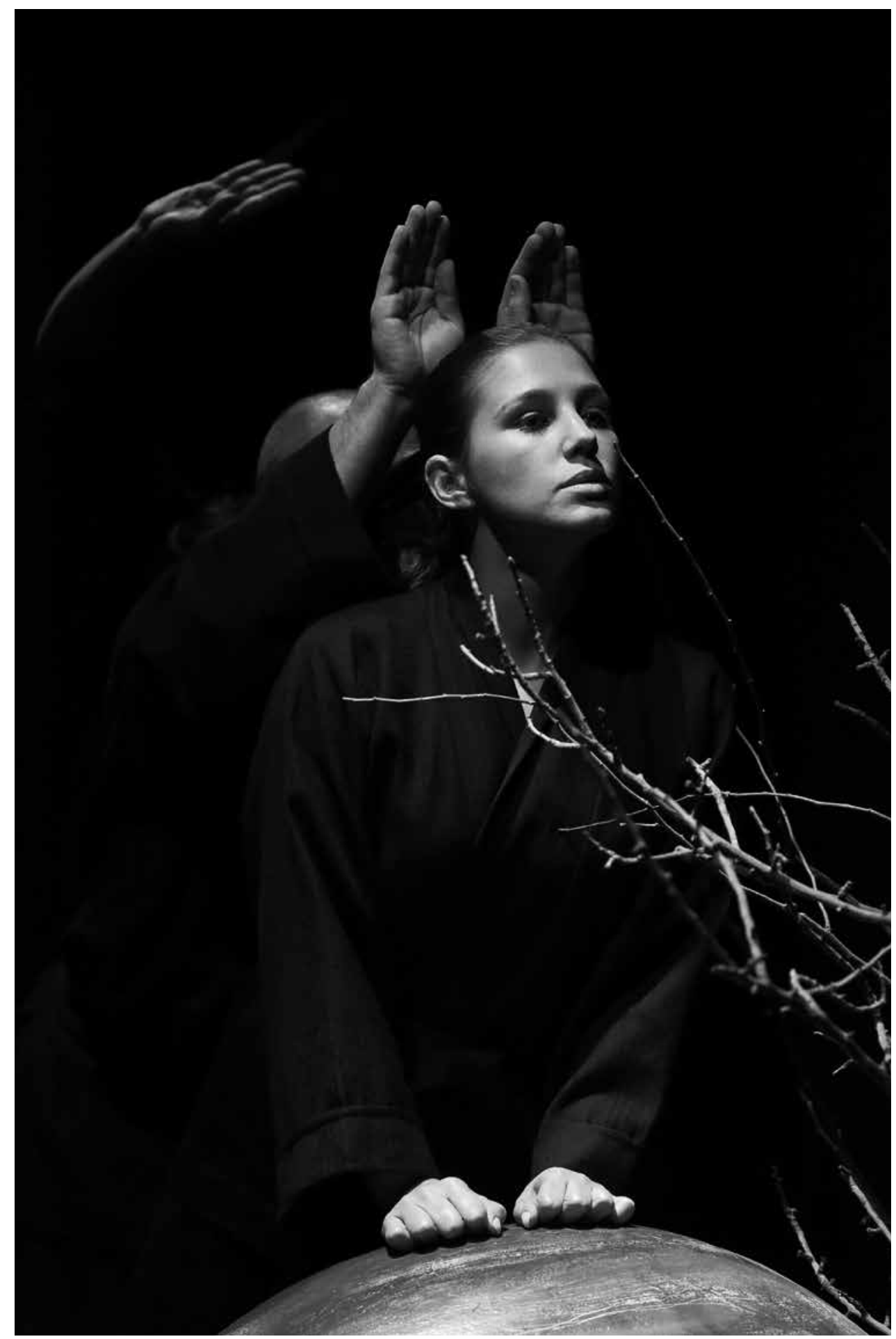

KITSUNE, ENC. RUI QUEIRÓS DE MATOS, TEATRO RIVOLI, 2016, [F] SUSANA NEVES 
de Coleccionadores, projecto vencedor da segunda edição da Bolsa de Criação Isabel Alves Costa. Depois de coleccionar retalhos de vida das pessoas com quem se cruzou no Vale do Minho, Raquel André senta-se connosco na plateia e mostra-nos o vídeo que testemunha esses encontros. Ficamos a conhecer alguns dos segredos que partilharam e somos também apresentados aos objectos que cada um lhe quis oferecer. Uma moeda de franco antiga, um vaso com um pé de camélia, uma colecção de cromos de futebol, um livro e um vinil do FMI, de José Mário Branco, são algumas das oferendas, objectos portadores de memórias, identidades, símbolos de rituais e modos de partilha.

Com os alemães Eva Meyer-Keller e Peter Waschinsky, reinventam-se modos de manipular objectos, materiais, marionetas e não-marionetas, pensando ainda em novas formas de começar o espectáculo e como sair de cena. Pulling Strings, de Eva Meyer-Keller, apresenta-nos uma coreografia de fios amarelos e cabos em teia que se ligam a objectos normalmente ocultos ou dissimulados no cenário, bastidores e áreas técnicas pelas suas funções utilitárias. Puxam-se os fios e accionam-se os objectos ou ligações técnicas, produzindo efeitos visuais e sonoros: acendem-se e apagam-se as luzes; um extintor é arrastado no chão, dando piruetas e soltando uma nuvem de fumo; fita Tesa preta descola-se do chão do palco, animando-se como uma serpentina e acabando por se colar ao caixote do lixo; os microfones ganham vida produzindo ruído e movimento, primeiro soltos e desengonçados, depois em pose nos tripés; os holofotes parecem interagir entre si, como se preparassem de novo o palco para o espectáculo. Os intérpretes vão desmontando o palco, acedendo por vezes ao apelo da matéria animada. Seguimos os fios e o movimento, e ruídos da matéria desvendam-nos uma outra percepção do espaço. Convidam-nos a reparar nas coisas.

Com Cabaret Berlinn, Peter Waschinsky propõe-nos um espectáculo com mãos nuas e objectos que ele nomeia «não marionetas»: uma bailarina feita de jornais amarrotados é Anna Pavlova, um pedaço de cartão é a Porta de Brandenburgo, uma galinha de borracha é Ginger Rogers. A ideia de manipulação é explorada através da paródia e num ambiente informal e intimista que recria os antigos cabarés. Quando entra em cena, avisa-nos de que um espectáculo de marionetas começa com uma pessoa viva escondida a manipular uma marioneta que dá as boas-vindas. Relembra-nos a diferença entre o actor vivo e a marioneta, confessando em alguns momentos que nem sempre as suas marionetas reagem ao seu pedido, como é o caso de dois macacos de corda que surgem como 
animais amestrados. Um toca tambor e é obediente; o outro toca pratos e precisa de pancadas no palco para reagir. Depois é a vez de um palhaço feito de tecido com lantejoulas que precisa de instruções para executar os movimentos: «up, up, up», repete, enquanto puxa os fios da sua marioneta irreverente. Se em Pulling Strings tínhamos intérpretes e matérias sem conseguirem sair de cena, em Cabaret Berlinn Peter Waschinsky experimenta várias formas de começar o espectáculo, interrogando o público para decidir as próximas etapas: «Did something happened? Can I do something else?»

Virada para Oriente, chega a mais recente criação das Marionetas do Porto. Kitsune, que significa «raposa» em japonês, desafia-nos a uma reflexão sobre a morte, que é acima de tudo um elogio da vida e um convite para restaurar rituais. Um espectáculo de contemplação, onde se evoca o culto da natureza, o despojamento e o desapego do eu inerente às filosofias zen orientais, que insistem na libertação da angústia da morte. «Olhar a morte nos olhos, servir-lhe uma sopa quente e dar-lhe a mão», é a divisa proposta. Uma paisagem de Inverno com árvores nuas, uma casa rodeada de neve e uma pedra negra oval. Três intérpretes vestidos de kimonos escuros entram em cena, criando figuras zoomórficas: uma ave e um animal felino surgem a partir de uma dança de movimentos lentos, fluidos e harmoniosos. São corpos ligados à terra, como no teatro tradicional japonês: joelhos flectidos, ancas e ombros recuados e mãos que indicam o caminho, num equilíbrio do gesto minimalista e controlado. Manipulam fios invisíveis, que anunciam o próximo objecto a ocupar a cena: um pássaro branco preso a um fio vermelho, movido pelos três intérpretes. Corta-se o fio do pássaro e as mãos continuam a manipular as matérias ausentes.

Uma convenção de ventríloquos, também eles marionetas peculiares, encerrou este festival empenhado em esgaçar os limites da marioneta. A última criação de Gisèle Vienne, A Convenção dos Ventríloquos, retoma o tema escolhido em Jerk, onde o ventríloquismo lhe permitiu experimentar as relações de associação e dissociação da voz e do corpo. Inspirada na Convenção Internacional de Ventríloquos do Kentucky, Gisèle Vienne recriou este evento em palco, com nove personagens que se multiplicam em vinte e sete vozes. As vozes dos bonecos confundem-se forçosamente com as vozes dos ventríloquos, sendo ainda emaranhadas pelas vozes interiores, que pairam como fantasmas, num labirinto de memórias e abismos emocionais. Arte da dissimulação e da alteridade, o ventriloquismo move-se como o teatro de marionetas num universo de duplos, 


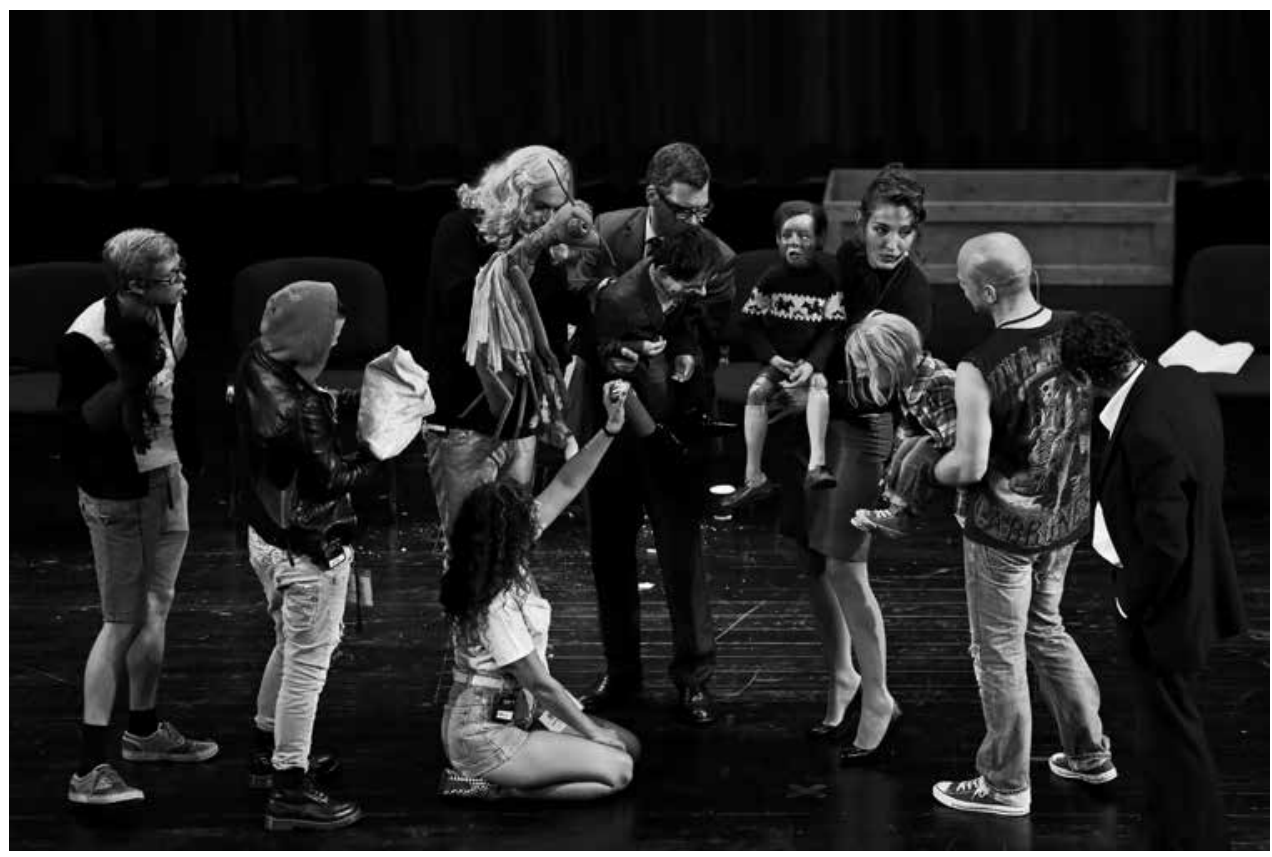

A CONVENC̣Ão DOS VENTRÍLOQUOS, ENC. GISĖLE VIENNE, TEATRO RIVOLI, 2016, [F] SUSANA NEVES

onde a matéria partilha o corpo e a voz com o intérprete, lugar propício para expandir a força, a vulnerabilidade e a excentricidade das personagens de Gisèle Vienne e o seu questionamento identitário.

Reparar nas coisas e sentir os corpos que são forçosamente matéria foram alguns dos desafios destes festivais de marionetas e formas animadas, despertando-nos para o modo como os objectos são portadores de inquietações humanas, veículos para resgatar memórias, rituais e histórias de vida. A marioneta representa a perda, a ausência. Os mortos que perdemos, os deuses que evocamos para incarnar a sua ausência, o membro amputado que se torna prótese, o objecto a que a criança se agarra quando a mãe se ausenta (Winnicott). Nos festivais de marionetas, vários são os exemplos de espectáculos onde animar objectos já não é apenas representar a vida, mas manifestar a presença da matéria que, independentemente do intérprete ou movida por ele, nos estimula percepções novas. A forma animada deixou de se limitar ao corpo ficcional, ampliando-se ao palco inteiro, encontrando a sua vitalidade nos materiais, nos elementos de cenografia, nos objectos esquecidos, na sucata, nos souvenirs, no quotidiano, mantendo-se ainda um veículo de memórias, portador de uma dimensão sagrada, mediador entre o mundo dos vivos e dos mortos. 